\title{
Catarata polar anterior piramidal deslocada para a câmara anterior causando edema de córnea -Relato de caso
}

\author{
Corneal edema caused by a pyramidal anterior polarcataract dislocated to the anterior \\ chamber-CaseReport
}

Ramon Coral Ghanem ${ }^{1}$

Vinícius Coral Ghanem ${ }^{1}$

Emir Amin Ghanem²

\section{RESUMO}

Cataratas polares anteriores piramidais são opacidades cônicas que se projetam para a câmara anterior a partir da cápsula anterior do cristalino. Na grande maioria dos pacientes a opacidade permanece aderida e estável durante toda a vida. O objetivo deste trabalho é documentar uma manifestação incomum desse tipo de catarata: a deiscência espontânea das pirâmides para a câmara anterior causando descompensação endotelial e edema corneal bilateral. Relatamos o caso de uma paciente feminina, de 66 anos, branca, que apresentava edema corneal localizado inferiormente no olho direito associado à lesão nodular branco-esclerótica compatível com a pirâmide anterior da catarata polar. O olho esquerdo apresentava edema corneal difuso intenso e presença de uma catarata polar anterior com a região piramidal deslocada para a câmara anterior. Sabe-se que a pirâmide anterior pode permanecer inabsorvida na câmara anterior por longo período, pois é composta de tecido colágeno denso. Isto causa perda endotelial progressiva e edema corneal e deve ser considerada indicação de remoção cirúrgica da catarata polar anterior e de seu fragmento. Ressalta-se, também, a importância do bom senso no julgamento das cataratas polares anteriores, considerando-se tamanho da opacidade, simetria das opacidades e componente cortical associado, na tentativa de se evitar ambliopia.

Descritores: Catarata/congênito; Edema da córnea; Segmento anterior do olho; Células epiteliais/patologia; Cristalino/patologia; Ambliopia/prevenção \& controle; Relato de casos

\section{INTRODUÇÃ̃O}

Cataratas piramidais anteriores são opacidades cônicas que se projetam para a câmara anterior a partir da cápsula anterior do cristalino. Têm origem similar às cataratas polares anteriores (CPA) comuns, mas são maiores em diâmetro e altura. São congênitas, na maioria das vezes bilaterais e assimétricas, ocorrendo geralmente em pacientes saudáveis, sem outras anormalidades sistêmicas ou oculares ${ }^{(1-2)}$. Atualmente, sabe-se que as cataratas polares anteriores estão associadas à alta morbidade visual, principalmente pela freqüente associação com estrabismo, anisometropia e ambliopia(2).

O objetivo deste trabalho é documentar uma manifestação incomum das CPA piramidais: a deiscência espontânea das pirâmides anteriores para a câmara anterior causando descompensação endotelial e edema corneal bilateral. 


\section{RELATO DE CASO}

Paciente feminina, de 66 anos, branca, foi atendida no Hospital de Olhos Sadalla Amin Ghanem referindo baixa acuidade visual (AV) em ambos os olhos desde a infância, com piora progressiva da AV do olho esquerdo (OE) há cerca de 3 anos. Negava antecedentes sistêmicos e oculares traumáticos. Os antecedentes pessoais e familiares nada revelaram.

Apresentava AV de 0,3 no olho direito (OD) e movimento de mãos no OE, sem melhora com correção. No OD, observava-se densa opacidade polar anterior e opacidade cortical adjacente, edema corneal inferior moderado e presença de um corpo estranho nodular branco-esclerótico, solto na câmara anterior, em contato com a superfície posterior da córnea e anterior da íris, na região inferior do ângulo camerular, consistente com o pólo piramidal da CPA (Figura 1). O fundo de olho era normal. No OE, observava-se intenso edema corneal difuso, com neovascularização corneal profunda que dificultava a visualização das estruturas oculares e o exame do fundo de olho. Podia-se observar, entretanto, a presença de uma CPA, com a região piramidal deslocada para a câmara anterior. A pressão intra-ocular era normal em ambos os olhos.

\section{DISCUSSÃO}

As CPA representam cerca de 13\% das cataratas congênitas $^{(2)}$. São produzidas por proliferação do epitélio capsular anterior e por possível transformação deste em células fibroblásticas que produziriam colágeno subepitelial ${ }^{(3)}$.

São geralmente esporádicas ${ }^{(1)}$, entretanto vários casos familiares já foram descritos, tanto autossômicos dominantes quanto recessivos ${ }^{(4-5)}$. Apesar da maioria dos casos de CPA ser isolada, já foram descritas associações oculares com microftalmia, aniridia, retinopatia da prematuridade, retinoblas-

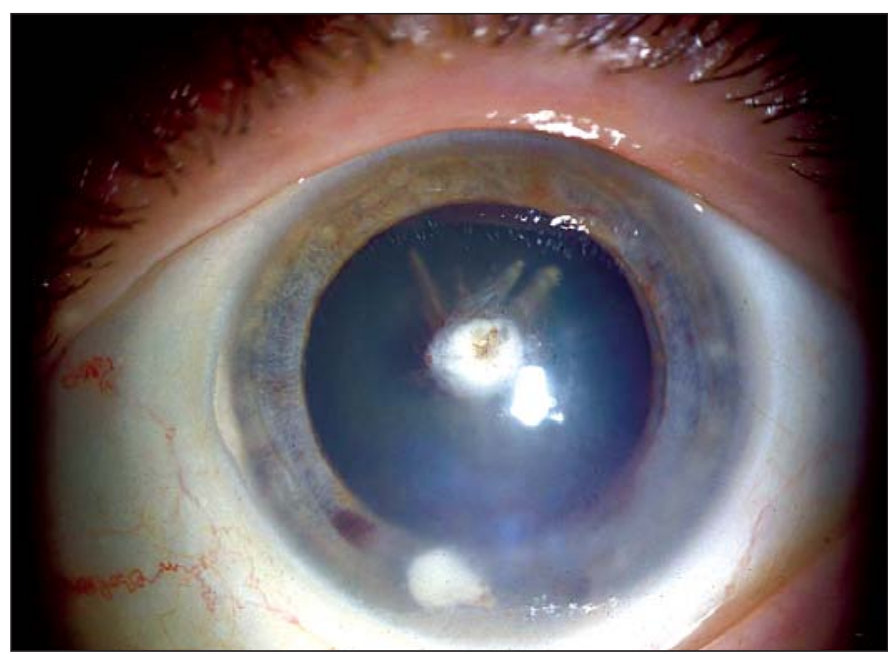

Figura 1 - Catarata polar anterior com opacidade cortical adjacente presença do pólo piramidal da catarata polar solto na câmara anterior causando edema corneal inferior (iluminação difusa) toma uni e bilateral, anomalia de Peters, persistência da membrana pupilar, entre outras ${ }^{(2,6-7)}$

Na grande maioria dos pacientes com CPA, a opacidade permanece estável durante toda a vida. No entanto alguns casos podem desenvolver opacificação cortical adjacente ao componente polar ${ }^{(1)}$ ou crescimento progressivo do componente $\operatorname{polar}^{(8)}$, o que pode facilitar o desenvolvimento de ambliopia. Alta incidência de morbidade visual foi descrita em 63 pacientes com $\mathrm{CPA}^{(2)}$. Estes autores concluíram que as maiores causas de ambliopia são a assimetria das opacidades polares, a anisometropia e o estrabismo. Eles encontraram uma associação com o tamanho da opacidade, o que também foi observado por outro autor ${ }^{(1)}$, sendo que opacidades maiores que $2 \mathrm{~mm}$ seriam potencialmente ambliogênicas. Os pacientes com ambliopia ou com possibilidade de desenvolvê-la, devem ser tratados com cirurgia e tratamento antissupressivo.

Na grande maioria dos pacientes, a pirâmide anterior permanece aderida à cápsula anterior. Deiscência espontânea da pirâmide anterior foi relatada em apenas dois outros $\operatorname{casos}^{(9-10)}$, ambos em pacientes indianos. No primeiro caso ocorreu deiscência espontânea não associada a edema corneal ${ }^{(9)}$; no segundo, o quadro ocular era similar ao que apresentamos, porém unilateral $^{(10)}$. Manobras cirúrgicas também podem provocar o descolamento da pirâmide anterior da cápsula do cristalino durante a extração da CPA piramidal, como descrito previamente em dois pacientes ${ }^{(11)}$. Em um desses casos, a pirâmide anterior permaneceu na câmara anterior após a cirurgia e causou hifema espontâneo recorrente. Os autores não observaram reabsorção do fragmento durante os três anos de acompanhamento pósoperatório. Deiscência do pólo anterior também foi relatada anos após um agulhamento (needling) para a remoção do cristalino ${ }^{(12)}$. Esses autores demonstraram o cristalino reabsorvido, fibrose da cápsula posterior e o fragmento polar anterior solto na câmara anterior, cinco anos após a cirurgia. Surpreendentemente, a córnea em contato com o fragmento apresentava-se sem edema.

No caso que estamos relatando, havia edema na região em contato com a pirâmide anterior em ambos os olhos. Lesão endotelial causada por um corpo estranho intracamerular não metálico deve-se, principalmente, a sua mobilidade e regularidade de superfície ${ }^{(13)}$. Neste caso, o tempo de contato do fragmento com o endotélio e a idade do paciente, levando-se em conta a redução do número de células endoteliais com a idade, são fatores que devem ser relacionados ao edema corneal. Concluindo, a lesão endotelial progressiva, causada por um corpo estranho de reabsorção lenta, como nessa situação, é uma indicação de remoção cirúrgica da CPA e de seu fragmento.

A ocorrência de deiscência bilateral das pirâmides anteriores não havia sido descrita previamente. Apesar da raridade deste fato, o acometimento do olho contralateral deve sempre ser lembrado nos casos unilaterais, sendo prudente o seguimento regular desses pacientes.

Finalmente, ressalta-se a importância do bom senso no julgamento das CPA, considerando-se tamanho da opacidade, simetria das opacidades e componente cortical associado, além do tratamento adequado de possíveis complicações. 


\section{ABSTRACT}

Pyramidal anterior polar cataracts are conical opacities that project into the anterior chamber from the anterior capsule of the lens. In the vast majority of patients the opacity remains bound and stable throughout life. We report an unusual complication of this type of cataract: spontaneous dehiscence of the pyramids to the anterior chamber causing bilateral endothelial damage and corneal edema. 66-year-old white woman presented with inferior corneal edema in the right eye and diffuse corneal edema in the left eye. A white nodular lesion was observed in the inferior angle in both eyes compatible with the pyramidal pole of the anterior polar cataract. The anterior pyramid can remain unabsorbed in the anterior chamber for long periods because it is composed of dense collagen, causing progressive endothelial cell loss and corneal edema. Therefore, it is an indication for extraction of the cataract and its anterior pole. In addition, we remind of the possibility of ambliopia, which is related to the size of opacity, symmetry of opacities, and superimposed cortical component.

Keywords: Cataract/congenital; Corneal edema; Anterior eye segment; Epithelial cells/pathology; Lens, crystalline/pathology; Amblyopia/prevention \& control; Case report

\section{REFERÊNCIAS}

1. Wheeler DT, Mullaney PD, Awad A, Zwaan J. Pyramidal anterior polar cataracts. Ophthalmology. 1999;106(12):2362-7. Comment in: Ophthalmology. 2001;108(3):430-1.

2. Jaafar MS, Robb RM. Congenital anterior polar cataract: a review of 63 cases. Ophthalmology. 1984;91(3):249-54.

3. Henkind P, Prose P. Anterior polar cataract: electron-microscopic evidence of collagen. Am J Ophthalmol. 1967;63(4):768-71.

4. Ionides A, Berry V, Mackay D, Shiels A, Bhattacharya S, Moore A. Anterior polar cataract: clinical spectrum and genetic linkage in a single family. Eye. 1998;12(Pt 2):224-6.

5. Merin S. Congenital cataracts. In: Goldberg MF, editor. Genetic and metabolic eye disease. Boston: Little Brown: 1974. p.337-9.

6. Hilles DA, Carter BT: Classification of cataracts in children. Int Ophthalmol Clin. 1977;17(4):15-29.

7. Brown GC, Shields JA, Oglesby RB. Anterior polar cataracts associated with bilateral retinoblastoma. Am J Ophthalmol. 1979;87(3):276-7.

8. Nelson LB, Calhoun JH, Simon JH, Harley RD. Progression of congenital anterior polar cataracts in childhood. Arch Ophthalmol. 1985;103(12):1842-3.

9. Thomas R, Gopal KSS, George JA. Anterior dislocation of the pyramidal part of a congenital cataract. Indian J Ophthalmol. 1985;33(1):51-2.

10. Shah UN, Garg P, Vemuganti GK. Corneal edema with dislocated anterior polar cataract. Am J Ophthalmol. 2002;133(3):399-401.

11. Jampol LM, Kass M, Dueker D, Albert DM. Anterior polar cataracts. Am J Ophthalmol. 1974;78(1):95-7.

12. Brown N, Ellis P. Anterior polar pyramidal cataract presenting as an anterior chamber foreign body. Br J Ophthalmol. 1972;56(1):57-9.

13. Archer DB, Davies MS, Kanski JJ. Non-metallic foreign bodies in the anterior chamber. Br J Ophthalmol. 1969;53(7):453-6.

\section{$7^{\circ}$ CONGRESSO DE OFTALMOLOGIA E $6^{\circ}$ CONGRESSO DE AUXILIAR DE OFTALMOLOgIA DA USP}

\section{6 a 28 de Novembro de 2004 \\ Centro de Conveng̨öes Rebouças S.Paulo - SP}

INFORMAÇÕES: Tel/Fax.: (1 1 ) 5539-2186

E-mail: congressousp@terra.com.br 